\title{
FIRST PAGE
}

Title: What is special about a Paediatric Liaison Child and Adolescent Mental Health service?

Author: M Elena Garralda

Address:

Professor Elena Garralda, Academic Unit of Child and Adolescent Psychiatry, Imperial

College London - St Mary's Campus, Norfolk Place, London W2 1PG -

e.garralda@imperial.ac.uk

Abbreviated (running) title: What is special about PL CAMHS?

Author for correspondence: Professor E Garralda, Academic Unit of Child and Adolescent Psychiatry, Imperial College London - St Mary's Campus, Norfolk Place, London W2 1PG e.garralda@imperial.ac.uk

October 2015 


\section{Key Practitioner Message:}

- There is very little information about Paediatric Liaison Child and Adolescent Mental Health Services. This report is a particularly large and comprehensive description of such a service

- Most referrals came from paediatricians, about two-thirds were for psychosomatic problems or difficulties adjusting to illness and the majority had a child psychiatric diagnosis.

- There were indications of differences from community CAMHS in referral sources and problems and in diagnostic breakdown, as well as shorter time to assessment and higher service take up rates in the PL group

- Hospital PL-CAMHS represent a distinct contribution to the provision of truly comprehensive CAMHS

\section{WHAT IS SPECIAL ABOUT A PAEDIATRIC LIAISON CAMH SERVICE? Background}

Although the paediatric population has long been known to be at high risk for psychiatric problems, recognition of psychopathology in paediatric clinics is limited (Garralda and Bailey, 1989; Glazebrook, Hollis, Heussler et al 2003). Child and adolescent paediatric and mental health services are often geographically apart and separately managed. Paediatric liaison child and adolescent mental health services (PL-CAMHS) have been developed to bridge this gap and to help increase recognition and management of psychiatric morbidity in the paediatric setting. Nevertheless, liaison services are still few and far between (Woodgate and Garralda, 2006) as well as highly vulnerable to financial health cost improvements (Shaw, Wamboldt, Bursch et al, 2006).

Earlier descriptions (Bingley, Leonard, Hensman et al, 1980; Black, McFadyen, Broster, 1990; Black, Wright, Williams, \& Smith, 1999; Shugart, 1991, Vandvick, 1994; Shaw et al, 2006) have outlined the nature of PL work. This commonly involves children presenting with a mixture of physical and psychological symptoms, a hospital base and good integration with both general and specialist paediatric services and with community CAMHS. 
A quick and efficient response to referrals is seen as central to the work, as is expertise in the management of joint medical and psychiatric problems within a multi-disciplinary framework.

PL CAMHS aim to improve family engagement with psychiatric and mental health services in children where the psychiatric problems occur in the context of physical dysfunction (Wrate and Kolvin, 1978) and to bring closer together the often diverging attitudes towards child psychiatric problems by paediatricians and child psychiatrists and their teams (Oke and Mayer, 1991; Kramer, 2009; Court 2014).

Hospital liaison mental health services for adult patients have been given renewed impetus in recent times by evidence that, in addition to beneficial effects on health and wellbeing, they can help reduce hospital admissions and health costs (Parsonage and Fossey, 2011), and there are similarly indications that PL-CAMHS intervention have the potential to reduce health costs (Garralda, 2015). Although there have been few rigorous evaluations of psychological interventions for mental health problems in children with physical illness, it is to be expected that those shown to be effective for managing and preventing emotional and behavioural problems in health children will also be effective when adapted to the presence of chronic illness (Bennett, Shafran, Coughtrey et al, 2015), and there is evidence of efficacy of psychological interventions for children with poorly explained medical symptoms, a particularly challenging group for paediatric services and a common reason for referral to paediatric liaison (Furness et al,2009; Garralda and Rask, 2015).

Work at the interface between paediatrics and CAMHS involves two main areas: emergencies, predominantly self-harm, and the mental health of children with physical illness or symptoms. Dedicated paediatric liaison CAMHS services, like their adult counterparts services, differ: some follow a combined emergency/self-harm and physical illness/psychological medicine service model; others offer a predominantly psychological medicine service and attend to the mental health needs of children with physical illness and symptoms whilst emergencies and deliberate self-harm are primarily managed by community CAMHS. The aim of this paper is to describe service process and clinical features of a contemporary PL-CAMH service operating within the physical illness or psychological medicine model in a tertiary specialist hospital, and to consider what is specific to PL work by comparing where appropriate clinical, process and outcome measures against published work on community/general CAMHS activity.

\section{Method}

The multi-disciplinary PL CAMHS consisted of one full time child and adolescent consultant psychiatrist and one part time family therapist. It serviced a UK tertiary specialist hospital in Nottingham (UK) with both generic and specialist paediatric beds and out-patient clinics. Two paediatric hospital units also had access to a separate uni-disciplinary psychological advice and children and young people with deliberate self harm were primarily managed by the local community CAMHS. The PL service covered all paediatric units and was not linked to selected paediatric clinics (Cottrell, 2015). Data was available for patients seen by the multi-disciplinary PL service between 2001 and 2008 and a decision was made to close the database once information had been collected on 800 children; $95 \%$ of cases had been closed to the service when the audit was conducted. A special pro-forma was developed to record information systematically on all patients seen and included a) demographic data 
(age, gender and ethnicity); b) details on the referrer and reasons for referral; c) clinical details including ICD-10 psychiatric diagnoses, duration of the problem, previous treatment and associated paediatric problems; d) service process measures: the time between referral and case take up, type and intensity of the PL intervention and discharge information; e) outcome data including global impressions by clinicians on the degree of improvement in child psychiatric and social status and on family function (satisfactory improvement, some change, unchanged) and completion of the clinician rated HoNOSCA CAMHS outcome scale (Yates, Garralda, Higginson, 1999; Garralda, Yates, Higginson, 2000) when appropriate. As this is a descriptive study, research ethics permission was not a requirement.

Data was analysed through frequency counts and where feasible through comparison with data on national (CAMHS mapping exercise; Wistow and Barnes, 2009) and community CAMHS work (Yates, et al, 1999; Garralda et al, 2000).

The CAMHS mapping exercise or atlas (Wistow and Barnes, 2009) documented CAMHS provision throughout England, with information on investment, staffing and activity and including clinical and process data, on all NHS funded CAMHS in England. Data from the year 2007 mapping is used in this report. This outlined activity data from 973/1047 (94\%) CAMHS, defined as generic (59\%), targeted on special groups (16\%), tier 4 (including highly specialised and in-patient teams; $22 \%$ ) and dedicated workers in non-CAMHS teams (3\%).

The community CAMHS data were extracted from an outcome evaluation of CAMHS use and included intake, process and outcome measures (Yates, et al, 1999; Garralda et al, 2000). The work was carried out in two CAMH out-patient clinics in London and in a day patient clinic attached to one of these, and documented 248 consecutive clinical referrals of children 3 to 18 years of age.

\section{Results}

PL CAMHS data was collected on 800 referrals between 2001 and 2008 . The age of children ranged from under 1 year ( 8 patients) to young adulthood (22 years: 2 patients); the mode was 14 years and the mean 11.9 (sd 3.8); 58\% were females and $80 \%$ of White ethnicity. Not all patients had recorded information on all audit items and consequently denominators vary.

\section{Service process information}

\section{TABLE 1 HERE}

Details on service process measures are given in Table 1. This describes the referral source, in or out patient status of referred children and degree of urgency. Consultant paediatricians from over 14 different paediatric teams referred cases, though, but five teams generated most referrals One third of children had had previous treatment for the problems leading to the PL referral.

In response to the referral the most common activity was immediate assessment cowork/consultation or out-patient appointment. Virtually all children were seen by the PL service within a month of referral and only $2 \%$ of families failed to attend for assessment. Table 1 describes the length and intensity of service involvement as well as discharge details and the fact that few families (4\%) dropped out of treatment. Social Services were involved 
as part of the intervention - mainly because of child protection concerns - in 117/715 or $16 \%$.

\section{Clinical data (Table 2)}

\section{TABLE 2 HERE}

The reasons for referral involved requests for both assessment and management and included psychosomatic problems such as unexplained medical symptoms, anorexia nervosa and encopresis, as well as poor adherence to medical treatment. Other referrals were for the assessment and management of psychiatric problems such as behavioural problems, anxiety, risk-assessment for deliberate self-harm and depression, habit disorders and psychoses.

From psychiatric assessments the majority of children had a psychiatric ICD-10 diagnosis (see Table 2 for diagnostic breakdown and duration of problems). One example is a child referred for problems in adjustment to illness who was given a psychiatric diagnosis of hyperkinetic disorder. The mood and anxiety disorders group comprised anxiety disorders in nearly half, affective or mood disorders in a fifth, and . About a third of the whole group also had psychiatric co-morbidity and poor school attendance was a common problem. In approximately half the referrals there were associated concerns about family function (in decreasing order: complex family problems, parenting and a variety of stressors such as bereavement and parental separation).

The most common paediatric disorders in children seen were epilepsy and neurological disorders $(137 / 721 ; 19 \%)$, diabetes $(82 ; 11 \%)$, gastrointestinal problems and cancer $(57$; $8 \%$ ).

\section{The Paediatric Liaison Service intervention}

The most frequent interventions are outlined in Table 1. The use of psychotropic medication involved stimulants, anti-depressants, anti-psychotics, melatonin and anxiolytics.

\section{TABLE 3 HERE}

It proved possible to obtain initial HoNOSCA scores - providing information on both symptoms and function - for half the referrals (Table 3 ). Use of this measure was not applicable for 326 (40\%) (it is not appropriate for very young children or when the main intervention is consultation or screening assessments) and forms were not completed on a further 111 children (13\%). Discharge HoNOSCAS were obtained for a quarter of referrals and in comparison with initial scores, they documented a statistically significant decrease or improvement in psychiatric symptoms and function. From global outcome assessments by PL staff (Table 3) some level of improvement was reported for most child psychiatric and family problems.

\section{Comparison with national/community CAMHS work}

When contrasted with data from the English national CAMHS mapping 2007 (Wistow and Barnes, 2009) the PL sample was comparable in age, gender and ethnicity. In the CAMHS national mapping the most common age group was also $10-14$ years, $41 \%$ were females, and $87 \%$ of White ethnicity. In the community CAMHS sample the mean age was 11.6 years (sd 3.9), 33\% were female and $65 \%$ of White ethnicity. 
Table 1 shows a number of differences between PL and the mapping and community CAMHS data, through the PL service receiving virtually all referrals from hospital paediatrics, assessing most children within a month of referral, having better attendance rates, and delivering fewer treatment sessions. The PLS diagnosed more children with adjustment/habit, somatoform disorders and anorexia nervosa and fewer with disruptive disorders (Table 2). HoNOSCA scores (Table 3) were higher in the PL group than in the community CAMHS sample, but the decrease in scores indicative of clinical improvement was similar in both.

\section{Discussion}

This is a particularly large and comprehensive description of paediatric liaison work. It shows that the majority of children were referred by a variety of paediatric teams and had psychiatric problems which were often complex, involving physical illness or symptoms and family dysfunction. Comparison with other CAMHS services indicates specificity of clinical presentations and work, making the PL service both distinctive and complementary of community CAMHS. The survey documents improvements in many families.

The nature of the work

In line with previous reports and in contrast with community CAMHS referrals, the majority of children seen by the PL service were referred by paediatric teams and had psychiatric problems in the context of physical illness, including difficulty adjusting to illness and/or adhering to medical treatments and psychosomatic presentations (Wrate and Kolvin, 1978; Black et al, 1999). Accordingly joint work with paediatricians and consultation were part of management in a substantial number. The complexity of the problems was underscored by the fact that in addition to the paediatric and psychiatric co-morbidity, school absence was noted in a third of children, and family problems in half. The service moreover responded to referrals from a wide variety of in-patient and out-patient hospital teams. This highlights the unique and important contribution of multi-disciplinary PL CAMH services, able to work with complex psychiatric problems across different paediatric units, and distinct from unidisciplinary psychological, counselling or health promotion services, which when available tend not to focus on child psychopathology and are often unequally funded and distributed across specialist paediatric units.

Differences from community CAMHS and outcomes

In spite of the fact that most children had diagnosable and many longstanding psychopathology, only a minority had had the benefit of previous help. Hospital based paediatric liaison teams thus contribute to filling the gap in mental health provision for a population at high risk for mental health problems, in a setting that makes it possible for children and families to accept help, as shown by the low default rates. For CAMHS to be truly comprehensive and attend to the needs of highly vulnerable groups, good provision of PL services would appear called for. A considerable percentage of children were referred for unexplained medical symptoms: in view of the high and potentially avoidable costs from unnecessary investigations and hospital admissions incurred by these children (Garralda, 2015), like their adult counterparts (Parsonage and Fossey, 2011) PL services may be expected to prove cost effective.

A number of children seen by the PL service were referred on to other clinical services for further work. Thus an aspect of PL is that of "bridging" the gap between paediatrics and other mental health service provision, as such complementing at a higher level of medical 
complexity the work of primary mental health workers or community "bridging" posts between primary health care and CAMHS and other clinical services (Hickey, Kramer, Garralda, 2009).

Given that PL work may primarily involve consultation rather than on-going work, formal before-after outcome measures of service use recommended for generic CAMHS proved appropriate for only a proportion of users. Whilst this and global clinician assessments of outcome suggested some level of clinical improvement in most children and families, tentatively indicating the potential efficacy of the service, it will be important to complement this in future work with satisfaction child and family and referrer ratings (Garralda, 2009).

Strengths and Weaknesses

Strengths of this study are the large sample, comprehensive and systematic data collection of both service process and clinical features, the use of outcome measures and comparison with national and community CAMHS data. Weaknesses include the missing data characteristic of clinical work and the tertiary specialist nature of the service, which may not be fully representative of PL CAMHS linked to generic paediatric services.

Conclusions: This large systematic description of a PL psychological medicine service shows that child users commonly have characteristic and complex psychiatric problems, the work is specific and complementary of community CAMHS and interventions appear potentially effective in reducing morbidity

Acknowledgment: This paper is based on the data collected by Dr Karmen Slaweska-Hollis and her colleagues at the Nottingham PL CAMHS. Thanks are due to Nicole Hickey for her assistance with data analysis.

Study funding and Conflicts of Interest: Nil reported

Contributorship: The author confirms full access to all the data in the study and takes responsibility for the integrity of the data and the accuracy of the data analysis.

\section{References}

Bennett S, Shafran R, Coughtrey A et al (2015) Psychological interventions for mental health disorders in children with chronic physical illness: a systematic review. Archives of Disease in Childhood, 100, 308-16

Bingley L, Leonard J, Hensman S, Lask B, Wolff O (1980) Comprehensive management of children on a paediatric ward: a family approach. Archives of Disease in Childhood, 7, 555561

Black D, McFadyen A, Broster G (1990) Development of a psychiatric liaison service. Archives of Disease in Childhood, 65, 1373-1375

Black J, Wright B, Williams C, \& Smith R (1999) Paediatric liaison service. Psychiatric Bulletin, 23, 528-530

Cottrell D (2015) Prevention and treatment of psychiatric disorders in children with chronic physical illness. Archives of Disease in Childhood, 100,303-304 
Court A (2014) Paediatricians and psychiatrists working together: what works best? Archives of Disease in Childhood, 99, 708-711

Furness P, Glazebrook C, Tay J, Abbas K, Slaveska-Hollis K (2009) Medically Unexplained Physical Symptoms in Children: Exploring Hospital Staff Perceptions, 14, 575-587Glazebrook C, Hollis C, Heussler H, Goodman R, Coates L (2003) Detecting emotional and behavioural problems in paediatric clinics. Child Care Health and Development, 29, 141-149

Garralda M E and Bailey D (1989) Psychiatric disorders in general paediatrician referrals. Archives of Disease in Childhood, 64, 1727-1733

Garralda, ME, Yates, P, Higginson, I (2000) Child and Adolescent Mental Health Service Use: HoNOSCA as an outcome measure. British Journal of Psychiatry, 177, 52-58

Garralda ME (2009). Accountability of specialist child and adolescent mental health services. The British journal of psychiatry, 194, 389-91

Garralda ME - Cost effectiveness of Paediatric Liaison CAMH Services - e-letter British Journal of Psychiatry- http://bjp.rcpsych.org/content/190/1/81.2.e-letters (Ctr+F "Garralda") or http://bjp.rcpsych.org/content/190/1/81.2.e-letters\#cost-effectiveness-ofpaediatric-liaison-camh-services

Garralda ME, Rask CU (2015) Somatoform and related disorders. Chapter 72: In Rutter's Child and Adolescent Psychiatry, $6^{\text {th }}$ Edition. Editors: Thapar A, Pine D, Leckman L, Scott S, Snowling M, Taylor E. Wiley-Blackwell, London ISBN: 978-1-118-38196-0

Hickey, N, Kramer T, Garralda ME Developing the Primary Mental Health Worker (PMHW) Role in England (2010) Child and Adolescent Mental Health, 15, 23-29

Kraemer S (2009) "The menace of psychiatry": does it still ring a bell? Archives of Disease in Childhood, 94, 570-572

Oke S, Mayer, R (1991) Referrals to child psychiatry: A survey of staff attitudes. Archives of Disease in Childhood, 66, 862-865

Parsonage M, Fossey M (2011) Economic evaluation of a liaison psychiatry service (C) Centre for Mental Health. www.centreformentalhealth.org.uk.

Shaw RJ, Wamboldt M, Bursch B, Stube M (2006) Practice Patterns in Pediatric Consultation-Liaison Psychiatry - A National Survey. Psychosomatics 47, 43-49

Shugart, MA (1991) Child psychiatry consultations to pediatric inpatients: A literature review. General Hospital Psychiatry, 13, 325-336

Yates, P, Garralda, ME, Higginson, I (1999) Paddington Complexity Scale and Health of the Nation Outcome Scales for Children and Adolescents. British Journal of Psychiatry, 174, $417-423$ 
Vandvik, IH (1994). Collaboration between child psychiatry and paediatrics: The state of the relationship in Norway. Acta Paediatrica, 83, 884-887

Wistow, R. and Barnes, D. (2009) 'A profile of child and adolescent mental health services in England 2007/8.', Technical Report. Durham University, School of Applied Social Sciences, Durham. http://www.childrensmapping.org.uk/

Woodgate M, Garralda ME (2006) Paediatric liaison work by child and adolescent mental health services. Child and Adolescent Mental Health, 11, 19-24

Wrate, RM, \& Kolvin I (1978). A child psychiatry consultation service to paediatricians. Developmental Medicine and Child Neurology, 20, 347-356 
Table 1. Service process information: Paediatric Liaison (PL) and Mapping and Community CAMH (Child and Adolescent Mental Health) Services

\begin{tabular}{|c|c|c|c|}
\hline \multirow{2}{*}{$\begin{array}{c}\text { Referral source } \\
\text { Hospital Paediatrics }\end{array}$} & $\begin{array}{l}\text { Paediatric Li } \\
\mathrm{n}\end{array}$ & $\begin{array}{l}\text { ison CAMHS } \\
\%\end{array}$ & \multirow{2}{*}{$\begin{array}{l}\text { CAMHS \% } \\
\text { Mapping (1) } \\
\text { Community (2) } \\
14 \%(1) ; 11 \%(2)\end{array}$} \\
\hline & $740 / 772$ & $95 \%$ & \\
\hline $\begin{array}{r}\text { In-patients [Urgent] } \\
\text { Out-patients [Urgent] }\end{array}$ & $\begin{array}{ll}282 & {[230]} \\
490 & {[92]} \\
\end{array}$ & $\begin{array}{ll}36 \% & {[29 \%]} \\
63 \% & {[12 \%]} \\
\end{array}$ & \\
\hline Previous treatment & $225 / 657$ & $34 \%$ & $38 \%(2)$ \\
\hline \multicolumn{4}{|l|}{ Referrer } \\
\hline Consultant/Trainee Paediatrician & $535 / 770$ & $69 \%$ & \\
\hline Nurses & 122 & $16 \%$ & \\
\hline Others & 113 & $15 \%$ & \\
\hline \multicolumn{4}{|l|}{ Referring teams } \\
\hline Generic Paediatrics & $137 / 780$ & $18 \%$ & \\
\hline Rheumatology & 116 & $15 \%$ & \\
\hline Neurology & 111 & $14 \%$ & \\
\hline Gastroenterology & 90 & $12 \%$ & \\
\hline Diabetic services & 80 & $10 \%$ & \\
\hline Others & 246 & $31 \%$ & \\
\hline \multicolumn{4}{|l|}{ Response to referral } \\
\hline Immediate assessment & $278 / 775$ & $36 \%$ & \\
\hline Out-patient appointment & 167 & $22 \%$ & \\
\hline Co-work the case & 120 & $15 \%$ & \\
\hline Consultation to other professionals & 102 & $13 \%$ & \\
\hline Refer to other services & 66 & $9 \%$ & \\
\hline Arrange in-patient treatment & 5 & $0.6 \%$ & \\
\hline Other [did not attend] & $37[22]$ & $5[2 \%]$ & {$[25 \%](2)$} \\
\hline Seen $<1$ month from referral & $660 / 678$ & $97 \%$ & $53 \%(1)$ \\
\hline \multicolumn{4}{|l|}{$\begin{array}{l}\text { Primary intervention (not mutually } \\
\text { exclusive) }\end{array}$} \\
\hline Assessment & $263 / 760$ & $34 \%$ & $24 \%(2)$ \\
\hline Family Therapy & 261 & $34 \%$ & \\
\hline CBT, individual therapy & 161 & $21 \%$ & \\
\hline Psychotropic medication & 62 & $8 \%$ & \\
\hline Consultation/transferred & 166 & $21 \%$ & \\
\hline \multicolumn{4}{|l|}{ Duration of service involvement } \\
\hline Less than 1 month & $270 / 759$ & $35 \%$ & $21 \%(1)$ \\
\hline 1-3 months & 215 & $28 \%$ & $(1-12 M) 23 \%(1)$ \\
\hline 4-12 months & 210 & $27 \%$ & \\
\hline More than 1 year & 64 & $8 \%$ & $46 \%(1)$ \\
\hline $\begin{array}{l}\text { Number of sessions seen } \\
\text { (mean/sd) }\end{array}$ & $\begin{array}{r}(n=624) \\
5(7.9)\end{array}$ & & $8(8.3)(2)$ \\
\hline
\end{tabular}




\begin{tabular}{|r|c|c|c|}
\hline \multicolumn{1}{|l|}{ Discharge } & & & \\
\hline To Primary care & $252 / 679$ & $37 \%$ & \\
\hline To referrer & 198 & $29 \%$ & \\
\hline To Community CAMHS & 106 & $15 \%$ & \\
\hline To other services & 93 & $13 \%$ & \\
\hline Dropped out of treatment - died & $19-11$ & $4 \%$ & \\
\hline
\end{tabular}

CAMHS: Child and Adolescent Mental Health Services [Subcategories in Italics] CBT: Cognitive Behaviour Therapy

(1) CAMHS mapping data 2007 (Wistow and Barnes, 2009)

(2) Community CAMHS (Yates et al, 1999; Garralda et al, 2000) 
Table 2. Clinical profiles of referrals to the Paediatric Liaison service and comparison data from Mapping and Community CAMHS

\begin{tabular}{|c|c|c|c|}
\hline \multirow[b]{2}{*}{ Presenting problem } & $\begin{array}{l}\text { Paediatric Lia } \\
\quad \mathrm{n}\end{array}$ & $\begin{array}{l}\text { CAMHS } \\
\%\end{array}$ & $\begin{array}{ll}\text { CAMHS } \% \\
\text { Mapping } \\
\text { Community } \\
\end{array}$ \\
\hline & & & \\
\hline $\begin{array}{r}\text { Psychosomatic } \\
-[\text { Unexplained medical } \\
\text { symptoms }]\end{array}$ & $\begin{array}{l}275 / 771 \\
195\end{array}$ & $\begin{array}{l}35 \% \\
25 \%]\end{array}$ & \\
\hline $\begin{array}{l}\text { Adjustment to physical illness } \\
\text { - [Treatment non-adherence] }\end{array}$ & $\begin{array}{l}206 \\
104 \\
\end{array}$ & $\begin{array}{l}26 \% \\
13 \%] \\
\end{array}$ & \\
\hline Child psychiatric problems & 262 & $33 \%$ & \\
\hline $\begin{array}{ll}\text { Trauma } \\
\end{array}$ & 18 & $2 \%$ & \\
\hline Parental adjustment to illness & 9 & $1 \%$ & \\
\hline \multicolumn{4}{|l|}{ Primary psychiatric diagnosis } \\
\hline Adjustment \& habit disorders & $\begin{array}{c}235(192 \& 43) \\
/ 800\end{array}$ & $29 \%$ & $11 \%+(2)$ \\
\hline Mood \& anxiety disorders & 182 & $22 \%$ & $34 \%(1)$ \\
\hline $\begin{array}{r}\text { Somatoform \& Conversion } \\
\text { disorders }\end{array}$ & 135 & $16 \%$ & $<2 \%(2)$ \\
\hline Conduct/Hyperkinetic D & 59 & $7 \%$ & $28 \%(1)$ \\
\hline Anorexia nervosa & 52 & $6 \%$ & $2 \%(2)$ \\
\hline Other & 137 & $17 \%$ & \\
\hline $\begin{array}{l}\text { Duration of psychiatric } \\
\text { problems } \\
\qquad \text { Acute, }<6 \text { months }\end{array}$ & $129 / 720$ & $18 \%$ & \\
\hline $\begin{array}{r}6-12 \text { months } \\
12-24 \text { months } \\
\end{array}$ & $\begin{array}{l}175 \\
111 \\
\end{array}$ & $\begin{array}{l}24 \% \\
15 \% \\
\end{array}$ & \\
\hline$>24$ months & 305 & $42 \%$ & \\
\hline $\begin{array}{l}\text { School non-attendance } \\
\text { [ On and off }\end{array}$ & $\begin{array}{l}238 / 649 \\
102\end{array}$ & $\begin{array}{l}36 \% \\
15 \% \\
\end{array}$ & \\
\hline$<6$ months & 56 & $8 \%$ & \\
\hline$>6$ months & 77 & $11 \%$ & \\
\hline Excluded & 3 & 1\%] & \\
\hline Family problems & $433 / 770$ & $56 \%$ & \\
\hline
\end{tabular}

CAMHS: Child and Adolescent Mental Health Services. [Subcategories in Italics]

(1) CAMHS mapping data 2007 (Wistow and Barnes, 2009)

(2) Community CAMHS (Garralda et al, 2000) 
Table 3. Clinical outcomes : Paediatric Liaison and Community CAMHS

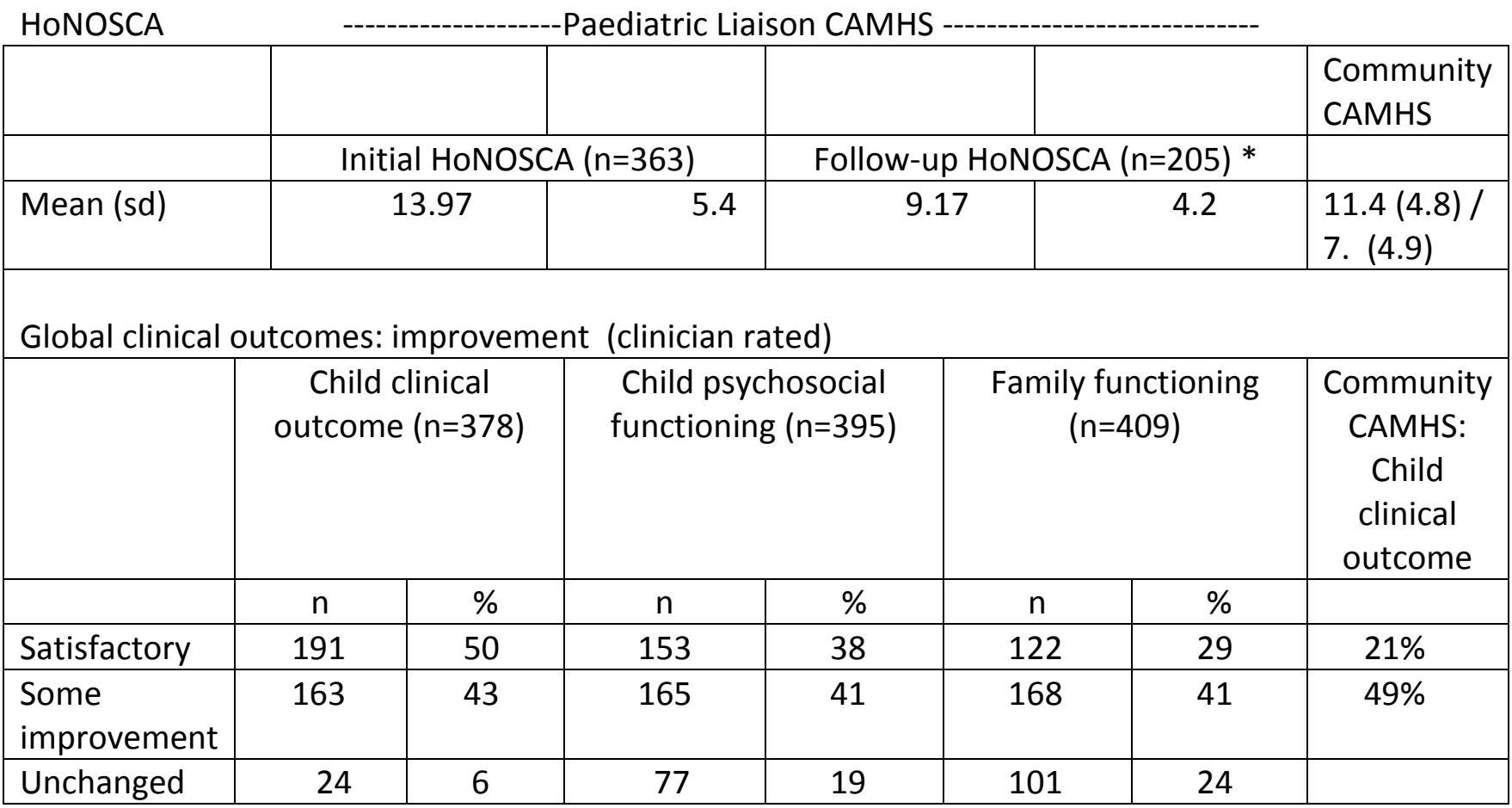

Community CAMHS (Garralda et al, 2000)

* Initial and Follow-up HoNOSCA (mean, sd) ( $n=192)$ : 14.79 (5.18) / 9.38 (4.23); Wilcoxon test comparing initial and follow-up values: $p=0.000$ 